\title{
Open
}

Review

\section{Friend or foe: the role of microRNA in chemotherapy resistance}

\author{
Haoran $\mathrm{LI}^{1,2}$, Burton B YANG ${ }^{1,2, *}$ \\ ${ }^{1}$ Sunnybrook Research Institute, Sunnybrook Health Sciences Centre, Toronto; ${ }^{2}$ Department of Laboratory Medicine and Pathobiology, \\ University of Toronto, Toronto, Canada
}

\begin{abstract}
Chemotherapy has been widely used in treating cancer patients. Despite the tremendous progress in cancer treatment achieved during the last decades, drug resistance still accounts for most of the tumor relapses in chemotherapy-treated patients. Emerging evidence shows that microRNAs play an important role in regulating the drug sensitivity of tumor cells. However, the mechanism of microRNA-mediated drug resistance is not fully understood. Current data suggest that microRNAs can be categorized as oncogenic or tumor-suppressive based on their functions and targets. In tumor cells undergoing drug treatment, microRNAs can function either by decreasing expression of genes associated with multiple drug resistance or by promoting escape from apoptosis and inducing tumor stem cell development. This review aims to provide an updated understanding of the role of microRNAs in regulating chemotherapy resistance and a discussion of potential therapeutic applications.
\end{abstract}

Keywords: cancer; chemotherapy; miRNA; stem cell; miR-17; stress response; drug resistance

Acta Pharmacologica Sinica (2013) 34: 870-879; doi: 10.1038/aps.2013.35; published online 29 Apr 2013

\section{Introduction}

Chemotherapy, together with surgery and radiotherapy, has been a main approach for cancer treatment. Most chemotherapeutic agents function by interfering with DNA replication and cell mitosis, inhibiting protein synthesis and inducing cell damage. Chemotherapy is often effective in diminishing rapid tumor cell growth as well as minimizing metastatic disease. In recent decades, tremendous efforts have been made to improve the efficacy of anticancer agents. For malignancies such as lymphoma, leukemia and small cell lung cancer, chemotherapy has been used as first-line therapy. As an adjuvant therapy, chemotherapy is widely used to prevent tumor recurrence by eliminating residual lesions. When used alone or combined with radiotherapy, neoadjuvant chemotherapy can even reduce tumor size before surgery, curing otherwise incurable patients. However, the development of drug resistance often results in the failure of chemotherapy, especially in advanced cancer patients. In general, there are two classes of drug resistance: inherent (natural) resistance and acquired resistance. Inherent resistance can be partially overcome by incorporating multiple agents into chemotherapy regimens, while acquired resistance to chemotherapeutic drugs accounts

\footnotetext{
* To whom correspondence should be addressed.

E-mail byang@sri.utoronto.ca

Received 2013-02-25 Accepted 2013-03-12
}

for greater than $90 \%$ of unsuccessful treatments in advanced cancer patients ${ }^{[1]}$. As a result of drug resistance, tumors often relapse more aggressively and metastasize to distant organs, leading to devastating outcomes. The mechanisms of chemotherapeutic drug resistance still remain largely unknown despite extensive investigation. The response of cancer cells to treatment indicates that chemotherapy resistance could be due to either genetic or epigenetic factors, including (1) overexpression of drug resistance-related proteins, (2) altered drug targets, (3) decreases in drug concentrations, and (4) escape from cell cycle checkpoints. Emerging evidence indicates that tumor angiogenesis and stem cell development are also responsible for chemoresistance.

It is known that cancer consists of a group of genetically heterogenetic cells. Chemotherapeutic drug treatment transforms predominant, fast-dividing cells into drug-resistant ones. These cells are thought to be the cause of subsequent tumor recurrence. During transformation, tumor cells undergo dramatic changes at the genetic and epigenetic level. MicroRNAs (miRNAs) have evolved as a major force in regulating gene expression and the phenotype of tumor cells because of their diverse functions in cell proliferation ${ }^{[2-4]}$, cell cycle $\operatorname{progression}^{[5-7]}$, survival ${ }^{[8,9]}$, invasion ${ }^{[10-12]}$, cell differentiation $^{[13,14]}$, and morphogenesis ${ }^{[15]}$. The activities of miRNAs are also regulated by non-coding RNAs. This was initially demonstrated by us using the 3'UTR of versican, which induces 
organ adhesion by modulating miRNA function ${ }^{[16,17]}$. Further studies indicated that a number of 3'UTRs possess the ability to regulate miRNA function ${ }^{[18-20]}$. In addition, pseudogenes and long non-coding RNAs can modulate miRNA function $^{[21,22]}$. This complicated network makes it difficult to understand the intrinsic mechanisms. Hence, there is a pressing need to decipher the molecular mechanism of miRNA-regulated drug resistance and its therapeutic implications. In this review, the role of microRNAs in anticancer drug resistance will be explored in light of current knowledge.

\section{MicroRNA as a key regulator in cancer}

MicroRNAs are non-coding RNAs of 20-22 bases in length that are broadly conserved across species. MiRNAs do not encode any proteins but regulate gene expression posttranscriptionally. Most miRNA loci are found in non-coding intronic transcription regions, but some are located in exonic regions $^{[23]}$. MiRNA genes are transcribed by RNA polymerase II (pol II) to primary miRNAs (pri-miRNAs), which are then processed by the Drosha-DGCR8 complex to release hairpin intermediate precursor miRNAs (pre-miRNAs). Pre-miRNA hairpins bind to exportin-5 and are exported to the cytoplasm where pre-miRNAs are cleaved by the RNase III-type enzyme Dicer. Normally, two miRNA strands, named miRNA-3p and miRNA-5p, are produced from opposite arms of one premiRNA $^{[23]}$. Previously it was thought that one strand is a mature miRNA and the other strand (the passenger strand) is degraded, but the current theory is that both arms can be selected as a mature miRNA in a tissue-specific context ${ }^{[24]}$. Mature miRNAs are incorporated into the RNA-induced silencing complex (RISC) to cleave target mRNA or repress mRNA translation by binding to its $3^{\prime}$-untranslated region ( $3^{\prime}$-UTR). However, some studies have shown that miRNAs can activate mRNA translation by binding to the $5^{\prime}$-UTR of their targets ${ }^{[25]}$. More recently, some miRNAs have been found to bind to decoy mRNAs in a RISC-independent way ${ }^{[26]}$ (Figure 1).

To date, research has demonstrated that miRNAs are linked to approximately 300 human diseases, especially cancer ${ }^{[27-30]}$. MiRNAs are broadly involved in cancer development, metastasis, angiogenesis and drug resistance. Because miRNAs are differentially expressed in human cancers, they can be categorized as oncogenic or tumor-suppressive according to their influence on cancer cell grow $\mathrm{th}^{[31-34]}$. Oncogenic miRNAs (oncomirs) induce cancer cell proliferation by down-regulating expression of tumor suppressor genes, whereas tumor suppressor miRNAs (mirsupps) inhibit cancer progression by targeting oncogenes post-transcriptionally (Figure 2). These miRNAs can be distinguished based on chromosome distribution, evolutionary rate and function. Oncomirs tend to be amplified in human cancers, whereas mirsupps are frequently cleaved $^{[35]}$. However, this dichotomous approach has its limitations. On one hand, it is important to note that miRNAs may act in a tissue-specific way such that a single miRNA type can be either an oncomir or a mirsupp in different types of tumors. For example, miRNA-17 was found to accelerate tumor devel-

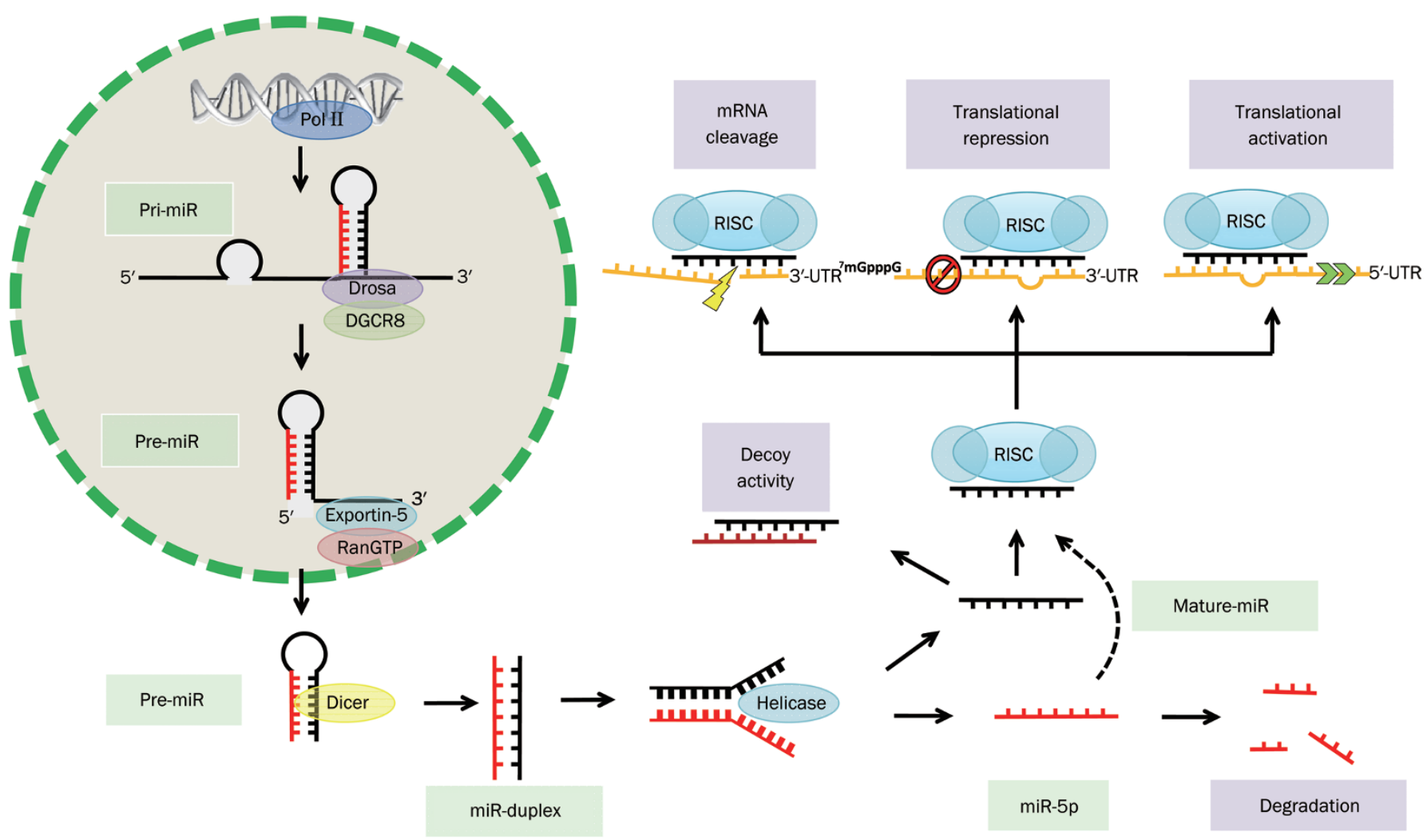

Figure 1. The mechanism of microRNA biogenesis and regulation of gene expression. 


\section{Conventional role of miRNA}
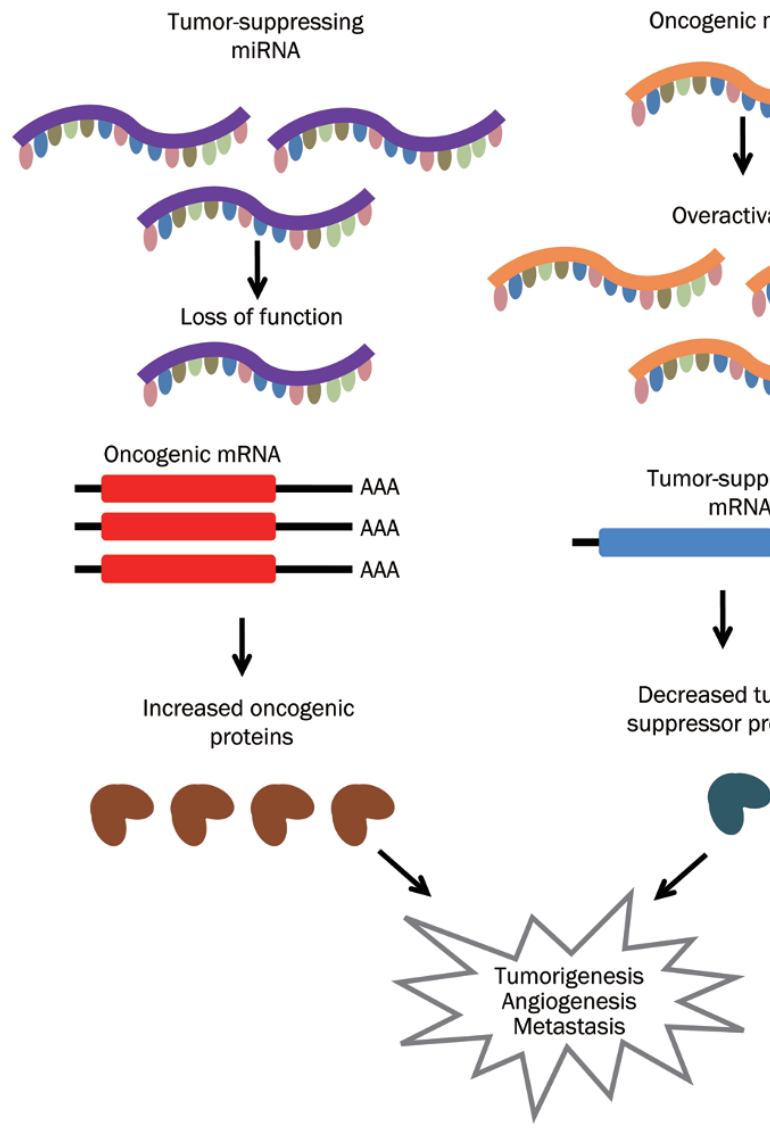

Oncogenic miRNA

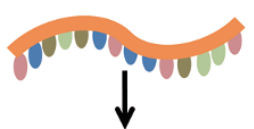

Overactivation
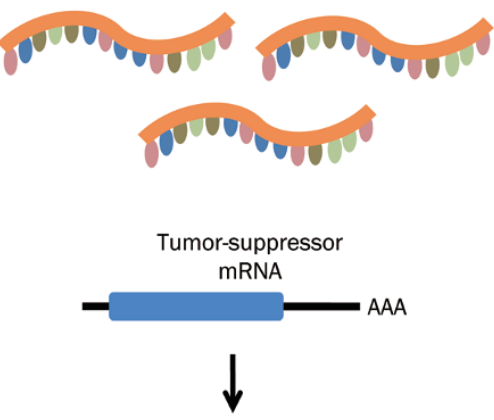

Decreased tumorproteins

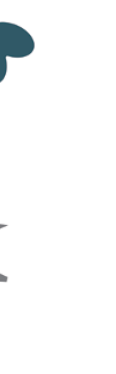

Buffing role of miRNA
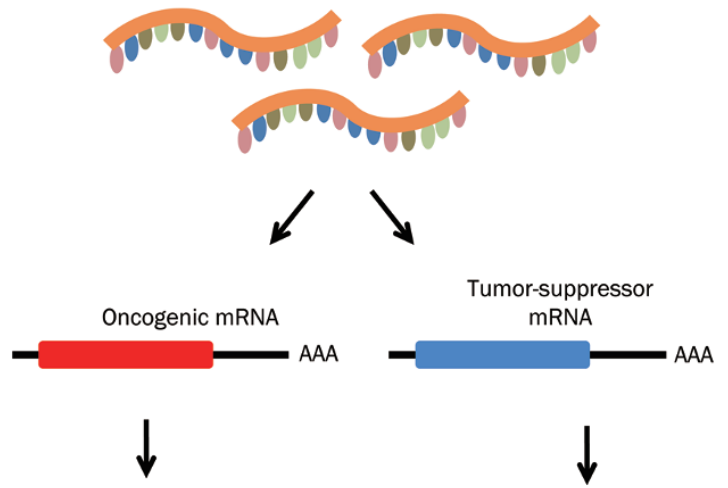

Inhibited oncogenic proteins

Inhibited tumorsuppressor proteins
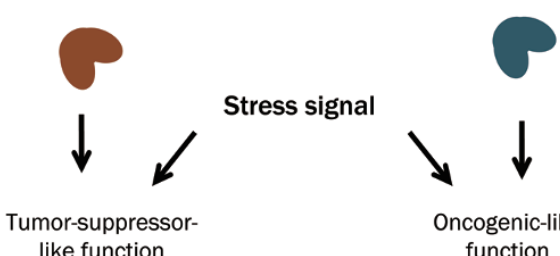

Stress signal

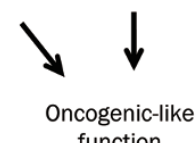

Figure 2. The role of microRNA in cancer.

opment in B-cell lymphoma, while it can suppress breast cancer growth by down-regulating AIB1 expression ${ }^{[36,37]}$. On the other hand, these and similar studies were based on experiments conducted in vitro where the body's immunity response and the tumor microenvironment are overlooked. Emerging models have shown that some miRNAs sensitize tumors to treatment while promoting tumor growth in vitro and that these miRNAs could even be used as predictive markers for clinical outcome ${ }^{[38]}$. As indicated above, we exploited miR-17's function in glioblastoma cells. We found that miR-17 targets the oncogene MDM2 and the tumor suppressor gene PTEN simultaneously, resulting in retardation of cell growth but prolonged cell survival ${ }^{[39]}$. Interestingly, the detected chemoresistance was partly a result of tumor stem cell generation ${ }^{[39]}$. MiR-17 also targets vimentin and GalNT7 and induces development of hepatocellular carcinoma ${ }^{[40]}$. Clearly, the biological effects of miRNAs in cancer are more complex than was once recognized (Figure 2).

\section{MicroRNAs regulate drug resistance-related proteins}

The term multiple drug resistance (MDR) refers to the condition when resistance to one drug is followed by resistance to multiple, often completely different, other drugs. Most known MDR proteins belong to the ATP-binding cassette (ABC) fam- ily, which includes P-glycoprotein (P-gp/MDR-1/ABCB1/ CD243), MDR-associated protein (MRP1/ABCC1) and breast cancer-resistant protein (BCRP/ABCG2). These proteins have similar trans-membrane domains and protect tumor cells from the influx of harmful drugs by pumping the drugs out ${ }^{[41]}$. To mimic the chemoresistant phenotype in vitro and study MDR mechanisms, drug-resistant cancer cell lines have been developed. Despite the change in protein levels, microarray analysis has disclosed transitions in miRNA expression. Some miRNAs, such as miR-19, miR-21, and miR-34a ${ }^{[42-44]}$, are elevated several fold in chemoresistance cell lines and are thought to play a role in cancer cell adaptation to chemotherapy. Meanwhile, reduced expression of some miRNAs is correlated with up-regulation of MDR proteins. These miRNAs usually control the expression of MDR-related proteins; thus, chemoresistance may result from down-regulation of these miRNAs. For example, miR-298 directly targets MDR-1 in a dose-dependent manner, resulting in decreased levels of P-gp. Moreover, overexpression of miR-298 reverses chemoresistance in breast cancer cells $^{[45]}$. It is notable that miR-27a activates MDR-1 indirectly in ovarian cancer, whereas MDR-1 can be directly targeted by miR-27a in leukemia ${ }^{[46,47]}$. The fact that miRNA has dual roles in regulating the same target is reinforced by these findings, and more details will emerge in the future that 
explain how miRNAs respond to different signaling processes in various tumors. The miRNAs that are reported to regulate MDR-1 are listed (Table 1). Identification of their function highlights a new approach for the development of gene therapy.

Other ABC family members such as MRP1 and BCRP also appear to be targets of miRNAs. MiR-326 was reported to modulate expression of MRP1 in VP-16 resistant cell lines, and induction of miR-326 reversed the resistance of VP-16 as well as doxorubicin ${ }^{[60]}$. BCRP is another drug resistance-related protein, which determines the pharmacokinetic properties of drugs in breast cancer cell lines. MiR-328 was found to target BCRP 3'-UTR and influence drug disposition accordingly in human breast cancer cells ${ }^{[61]}$. Because the MDR mechanism accounts for only some aspects of drug resistance, more experiments will be needed to explore the actual function of miRNAs in different types of malignancies. Nevertheless, the study of miRNA targeting drug resistance-related proteins will undoubtedly shed light on the therapeutic value of miRNAs.

\section{MicroRNAs alter drug targets}

MicroRNAs not only act in a cell-specific manner but also influence drug resistance in a drug-specific way. For example, elevated expression of miR-34a is associated with docetaxel resistance in breast cancer cell lines, while miR-34a conversely sensitizes Ewing's sarcoma cells to doxorubicin and vincristine ${ }^{[43,62]}$. Recent development of targeted therapies provides hope that successful cancer treatments are forthcoming. MiRNAs have been found to interfere with specific molecular targets blocked by medications. In non-small cell lung cancer cells, miR-126 efficiently binds to the 3'-UTR of vascular endothelial growth factor A (VEGFA), which is the target of the angiogenesis inhibitor bevacizumab. Furthermore, restoration of miR-126 enhances the sensitivity of tumor cells to anticancer agents, which implies the possibility of combined targeted therapy ${ }^{[63]}$. Mutated epidermal growth factor recep- tor (EGFR/HER1), a cell-surface receptor, is associated with a number of cancers. Therefore, it serves as an important target for anticancer drug therapy. Tyrosine-kinase inhibitors (eg, gefitinib, erlotinib) and monoclonal antibodies (eg, cetuximab, panitumumab) have been developed to inhibit EGFR signaling and approved to treat patients harboring EGFR mutations. It is notable that EGFR pathways crosstalk with some miRNAs during carcinogenesis and drug treatment. For example, EGFR mutations positively regulate miR-21, which in turn increases expression of EGFR ${ }^{[64,65]}$. Such a positive feedback loop is critical in maintaining physical homeostasis, but could also be the cause of drug resistance in EGFR inhibitor-treated patients. Similarly, miR-145 inhibits cancer cell growth by targeting EGFR, whereas EGFR suppresses miR-145 to promote tumorigenesis in animal models ${ }^{[66,67]}$. These findings reveal one aspect of the buffering role of miRNA that is subject to regulation by its own targets to maintain a balance between positive and negative signaling.

In addition, miRNAs can inactivate drugs by up-regulating downstream effectors of the same pathway. One cause of therapeutic resistance is inactivation of tumor suppressor PTEN, which allows over-activation of the PTEN/PI3K/AKT pathway. Numerous miRNAs target PTEN and function as oncomirs, including miR-17, miR-21, miR-144, and miR$214^{[39,68-70]}$. Another example of bypassing growth inhibition is the recruitment of insulin-like growth factor-1 receptor (IGF1), which was found in tumors that overexpressed miR$17-92^{[71]}$. Down-regulation of miRNAs targeting IGF1 leads to tumorigenesis, and restoration of the miRNAs causes growth inhibition of the tumor cells ${ }^{[72]}$. Future studies should address the predictive value of miRNA expression in personalized medicine. Overcoming drug resistance by using miRNAs that share the same targets as anticancer agents may also prove promising $^{[73]}$.

\section{MicroRNAs change drug concentrations}

The development of chemoresistance is marked by the loss of

Table 1. The miRNAs involved in the regulation of MDR-1.

\begin{tabular}{|c|c|c|c|}
\hline Tumor category & miRNA & Mechanism & Reference \\
\hline \multirow[t]{5}{*}{ Breast cancer } & miR-21 & Actively regulates MDR-1 and IAPs & [48] \\
\hline & $\operatorname{miR}-137$ & Targets Y-box binding protein-1 (YB-1) and suppresses MDR & [49] \\
\hline & miR-200c & Targets MDR-1 & {$[50]$} \\
\hline & miR-298, miR-1253 & Targets MDR-1 directly & [45] \\
\hline & miR-451 & Targets MDR-1 & [51] \\
\hline Glioblastoma & miR-221 & Targets MMP-9 and suppresses MDR & {$[52]$} \\
\hline Colon cancer & miR-145 & Targets MDR-1 directly & [53] \\
\hline \multirow[t]{4}{*}{ Ovarian cancer } & Let-7 & Regulates IMP-1 mediated stabilization of MDR-1 & [54] \\
\hline & $\operatorname{miR}-27 a$ & Targets HIPK2 and increases MDR-1 & [55] \\
\hline & miR-27a, miR-451 & Activates MDR-1 indirectly & {$[46]$} \\
\hline & miR-130a & Targets PTEN and activates MDR & {$[56]$} \\
\hline Liver cancer & miR-122 & Targets MDR-1 and MRP & {$[57]$} \\
\hline \multirow[t]{2}{*}{ Leukemia } & miR-27a, miR-331-5p & Targets MDR-1 directly & {$[47]$} \\
\hline & miR-138 & Suppresses MDR-1 & [58] \\
\hline Prostate cancer & miR-148a & Targets MSK1 and suppresses MDR & [59] \\
\hline
\end{tabular}


the drug transport system in cells that results in a decline in the drug concentration inside cells. Gap junction intercellular communications (GJIC) are broadly involved in the transportation of small molecules and second messengers. Gap junction constituents, such as transmembrane protein connexins (Cx), are often lost in cancer cells. Restoration of GJIC suppresses tumor progression and enhances drug sensitivity. The main antitumor function of GJIC relies on the bystander effect (BE), when cytotoxic molecules are transferred from target cells to neighboring cells through GIC, exposing more cells to chemotherapeutic agents ${ }^{[74]}$. MiR-1 and miR-206 have been shown to target connexins, which may lead to impaired GJIC ${ }^{[75,76]}$. Another study showed that RNA-binding protein Dnd1 counteracts the function of miR-1 and miR-206 by prohibiting them from associating with their targets ${ }^{[7]}$. These results verify that endogenous miRNAs are under the regulation of an intrinsic network. Consequently, systematic down-regulation of miRNAs also drives the development of drug resistance. It was reported that systemic RNA interference-defective-1 transmembrane family member 1 (SIDT1) facilitates intercellular transfer of miR-21, which promotes resistance to gemcitabine in human adenocarcinoma cells ${ }^{[78]}$.

In addition to influencing the bystander effect, miRNAs have an impact on cell receptors. The estrogen receptor (ER), which serves as the target of endocrine therapeutic agents such as tamoxifen and raloxifen, is regulated by let-7, miR-206, and miR-221 in breast cancer ${ }^{[79-81]}$. Interestingly, miR-206 and miR-221 are believed to be responsible for tamoxifen insensitivity, while induction of tamoxifen sensitivity by let-7 could be due to a different binding region. Accumulating evidence suggests that 1alpha,25-dihydroxyvitamin $\mathrm{D}_{3}\left[1,25(\mathrm{OH})_{2} \mathrm{D}_{3}\right]$ inhibits growth of many types of cancerous cells such as breast cancer and colon cancer. It was shown that miR-125b recognizes the 3'-UTR of the vitamin D receptor and abolishes its expression, resulting in a decrease in the anticancer effects of $1,25(\mathrm{OH})_{2} \mathrm{D}_{3}{ }^{[82]}$.

In addition to changing drug concentrations at the cellular level, miRNAs influence the pharmacokinetics of drugs in the whole body. For example, cytochrome P450 (CYP), a superfamily of drug-metabolizing enzymes, can be targeted by miR$27 b^{[83]}$. In breast cancer tissues, decreased miR-27b is accompanied by a high level of CYP1B1 protein responsible for docetaxel resistance in cancerous cells ${ }^{[83,84]}$. Accumulating evidence suggests that miRNAs may exert profound physiological effects on the regulation of the CYP family. For example, CYP1A1 was reported to be targeted by miR-892a, and CYP2J2 is inhibited by let- $7 b^{[85,86]}$. Recent data indicated that miRNAs repress CYP in a dose-dependent manner. In transgenic mice, knockdown of CYP3A by miRNA-based shRNA dramatically reduces enzymatic activity ${ }^{[87]}$. It is known that the liver plays a crucial role in catalyzing drugs. We found that miR-17 impairs nonalcoholic hepatic steatosis in transgenic mice by targeting PPAR-alpha, leading to damaged liver function [Liu et al, Unpublished data].

\section{MicroRNAs influence therapeutic-induced cell death}

Various anticancer drugs function by inducing intrinsic and extrinsic apoptosis in tumor cells ${ }^{[88]}$. The cellular response to apoptotic signaling can determine the outcome of treatment. There are two principal pathways leading to apoptosis: the mitochondrial intrinsic pathway and the transmembrane extrinsic pathway. The former pathway is mainly under the control of the Bcl-2 family, which includes more than 30 apoptotic regulating molecules ${ }^{[89]}$. A number of miRNAs participate in cell apoptosis via interaction with Bcl-2 family members. For example, miR-15/16, miR-21 and miR-125b were all shown to regulate $\mathrm{Bcl}-2$ protein, an anti-apoptotic factor. It was discovered that miR-15/16 induces apoptosis by targeting Bcl-2, whereas suppression of miR-15/16 promotes up-regulation of $\mathrm{Bcl}-2$ and resistance to tamoxifen in breast tumors ${ }^{[90]}$. Although miR-21 can bind to the 3'-UTR of Bcl-2 mRNA, it ultimately has an anti-apoptotic role in most tumors ${ }^{[91]}$. The reason for this might be that miR-21 has another target, the critical pro-apoptotic molecule Bax, in the same pathway. Down-regulation of Bax by miR-21 inhibits drug-induced apoptosis ${ }^{[92]}$. These results highlight another aspect of the buffering role of miRNAs, which interact with the whole signaling pathway by simultaneously controlling both upstream and downstream effectors. Another example is miR-125b, which targets both anti-apoptotic Bcl-2 and proapoptotic Bak1, conferring drug resistance and anti-resistance properties in different cancers ${ }^{[33,94]}$, which is consistent with our finding that miRNAs play different roles based on spatial and temporal contexts ${ }^{[39]}$ (Figure 2).

At the onset of apoptosis, multimeric pro-apoptotic proteins assemble into the apoptosome, which mediates the activation of the caspase reaction. The formation of the apoptosome is often inactivated in tumor cells ${ }^{[89]}$. Apaf-1 is an adaptor molecule that forms the backbone of the apoptosome. It was recently revealed that miR-155 negatively regulates Apaf-1 in lung cancer tissue and inhibits the sensitivity of cancer cells to cisplatin ${ }^{[95]}$. Other factors may also be involved in apoptosis. Experiments in our lab showed that breast cancer cells transfected with miR-199a-3p have significantly increased sensitivity to docetaxel treatment, as indicated by a prominent increase in sub- $\mathrm{G}_{1}$ apoptotic cells. We then demonstrated that this effect is due to the inhibition of caveolin-2 by miR$199 a-3 p^{[3]}$. Currently, there are over thirty miRNAs reported to participate in the regulation of cell cycle progression by modulating various pathways, such as RAS, AKT, E2F1, and $\mathrm{p} 53^{[6]}$. This research identifies a new type of miRNA-mediated drug resistance in cancer cells.

\section{MicroRNAs regulate angiogenesis}

We initially illustrated that endogenously expressed miRNAs can play an important role in tumor angiogenesis. In glioblastoma cells, miR-378 contributes to cell survival in vitro and tumor growth and vascularization in vivo by targeting SuFu and Fus-1 ${ }^{[96]}$. Aggressive angiogenesis helps tumor cells escape treatment and metastasize to distant organs. Recent 
studies have shown that a variety of miRNAs (eg, miR-126, miR-130a, miR-210, and miR-296), termed angiomiRs, regulate tumor angiogenesis ${ }^{[97]}$. For example, overexpression of miR-93 in U87 cells increases tube formation in vitro and neovascularization in vivo ${ }^{[98]}$. While many miRNAs function as pro-angiogenic regulators, some miRNAs can suppress tumor angiogenesis. In breast cancer, endogenous miR-126 inhibits endothelial cell recruitment and angiogenesis that are essential for metastasis by targeting insulin-like growth factor binding protein 2 (IGFBP2) ${ }^{[99]}$. In the well-studied miR-17 92 cluster, miR-92a was also identified as a negative regulator of angiogenesis that acts by down-regulating integrin alpha $5^{[100]}$.

A number of therapeutic approaches (bevacizumab, sorafenib, sunitinib, etc) that block the vascular supply to tumors have reached the clinic. However, only a fraction of patients benefit from treatment because tumors develop resistance to vascular endothelial growth factor (VEGF) inhibitors $^{[101]}$. Computational analysis predicted that at least 96 miRNAs are directly involved in VEGF regulation ${ }^{[102]}$. These miRNAs were shown to be associated with the efficacy of anti-VEGF treatment ${ }^{[103]}$. Apart from binding the $3^{\prime}$-UTR of VEGF mRNA, many miRNAs can mediate VEGF signaling pathway indirectly. It was demonstrated that aberrant regulation of von Hippel-Lindau tumor suppressor(VHL) induces hypoxia inducible factor-1(HIF-1) alpha activation, which promotes autocrine VEGF secretion in leukemia ${ }^{[104]}$. Over-activation of tumor-derived VEGF might be responsible for treatment failure. In glioblastoma cells, miR-17 was responsible for the activation of VEGF by activating the upstream factor HIF-1 alpha. Interestingly, these effects become dramatically significant when the tumor cells are starved or exposed to chemotherapy ${ }^{[39]}$. These findings favor the application of anti-angiogenesis therapy combined with chemotherapeutic agents. It is currently unclear how anti-VEGF therapy alone influences tumor growth. Further investigation of the involvement of miRNAs with tumor angiogenesis might provide more clues for optimizing the selection of anti-angiogenesis treatments.

\section{MicroRNAs in the generation of tumor stem cells}

Tumor stem cells (TSCs) have long been considered a cause of cancer recurrence during the treatment of cancer. TSCs are thought to be responsible for therapeutic resistance, tumor metastasis and relapse. Since being discovered in acute myeloid leukemia cells in 2003, TSCs have been reported in most tumor types ${ }^{[105]}$. In recent years, the relationship between miRNAs and TSCs has been confirmed with the identification of several miRNAs that control key biological properties of TSCs in breast cancer, prostate cancer and glioblastoma ${ }^{[106]}$. Song's group was the first to examine the relationship between miRNAs and breast cancer stem cells ${ }^{[107]}$. They analyzed the expression of let-7 in breast tumor-initiating cells and found that let-7 was dramatically reduced in TSCs. They then identified let-7 as a key regulator of tumor stem cell characteristics through silencing of H-RAS and HMGA2 ${ }^{[107]}$. Though methods to identify stem cells in cancer are controversial, CD44 and
CD133 have been widely used as surface markers of TSCs ${ }^{[107]}$. Interestingly, a recent study suggested that miR-34a inhibits TSCs formation in prostate cancer by directly repressing $\mathrm{CD} 44^{[108]}$, indicating that miRNAs might take part in the regulation of TSCs. In addition, some miRNAs possess the ability to promote the generation of TSCs by down-regulating tumor suppressors. In hepatocellular carcinoma, miR-130b is associated with TSC growth that leads to worse overall survival and more frequent recurrence of cancer in patients. The increased miR-130b occurs in parallel with the reduction of tumor protein 53-induced nuclear protein 1, a known miR-130b target. Furthermore, cells transfected with miR-130b have a higher resistance to chemotherapeutic agents ${ }^{[109]}$.

Tumor stem cells are believed to be capable of self-renewal and give rise to tumorigenesis. In glioblastoma cells, we found that cells transfected with miR-378 contain a large group of side population (SP) cells that have a high density of TSCs ${ }^{[110]}$. Overexpression of miR-378 enhances colony formation and cell survival, which is due to the up-regulation of stem cell marker Sox-2 ${ }^{[110,111]}$. Interestingly, cells harboring higher percentages of TSCs grow more slowly under normal conditions, but display significant survival advantages when stressed by treatment with anticancer agents ${ }^{[39]}$. Therefore, it is likely that miRNAs control the development of TSCs at multiple levels.

\section{Conclusion and perspective}

Are miRNAs friends or foes in cancer treatment? This question might be too broad to answer concisely. As discussed above, the effect of miRNAs in drug resistance might be positive or negative, or might even vary under different circumstances (Figure 3). Taking evolutionary conservation into consideration, the nature of miRNAs in physiological conditions could be more similar to buffering. Emerging data suggest that miRNAs are important for balancing different signaling processes and helping to maintain homeostasis ${ }^{[112]}$. It has been well established that cancer is a heterogeneous group of diseases. Thus, personalized medicine has evolved as a future direction in clinical oncology. Down-regulation of miRNA networks has been shown to be the root of cancer development. Therefore, therapeutic strategies should focus on rebalancing miRNA networks. Meanwhile, miRNA profiling will have promising diagnostic and prognostic value.

\section{Acknowledgements}

The authors thank Mr Shaan GUPTA for preparation of the article. Our studies were supported by grants from the Canadian Institutes of Health Research (MOP-102635, MOP-111171) and the Natural Sciences and Engineering Research Council of Canada (NSERC, 227937-2012) to BBY, who is the recipient of a Career Investigator Award (CI 7418) from the Heart and Stroke Foundation of Ontario. HL is a recipient of the Connaught International Student Award.

\section{References}

1 Gong J, Jaiswal R, Mathys JM, Combes V, Grau GE, Bebawy $M$. Microparticles and their emerging role in cancer multidrug 


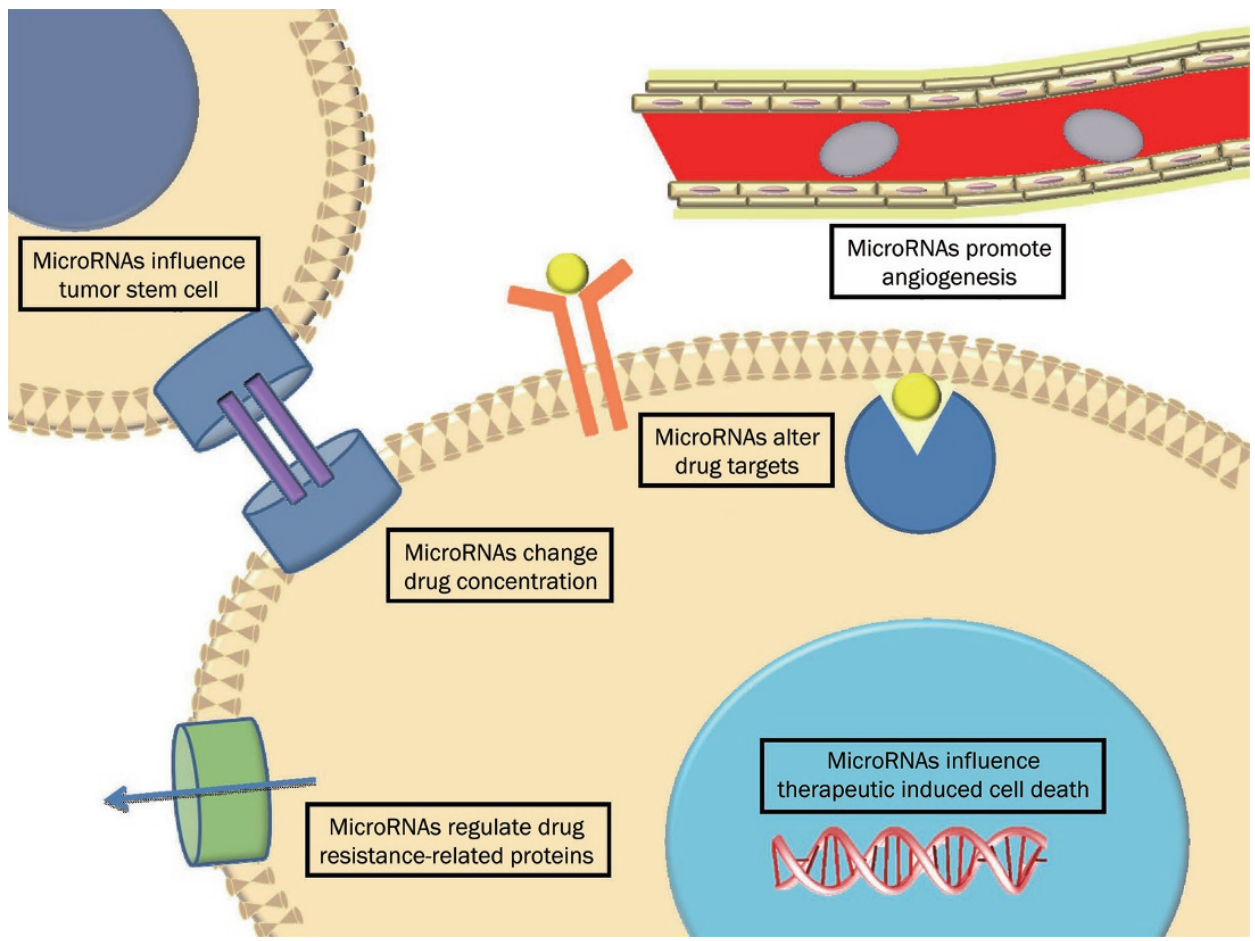

Figure 3. MicroRNAs regulate drug resistance.

resistance. Cancer Treat Rev 2012; 38: 226-34.

2 Viticchie G, Lena AM, Latina A, Formosa A, Gregersen LH, Lund AH, et al. MiR-203 controls proliferation, migration and invasive potential of prostate cancer cell lines. Cell Cycle 2011; 10: 1121-31.

3 Shatseva T, Lee DY, Deng Z, Yang BB. MicroRNA miR-199a-3p regulates cell proliferation and survival by targeting caveolin-2. J Cell Sci 2011; 124: 2826-36.

4 Yu B, Zhou S, Wang Y, Qian T, Ding G, Ding F, et al. miR-221 and miR222 promote Schwann cell proliferation and migration by targeting LASS2 after sciatic nerve injury. J Cell Sci 2012; 125: 2675-83.

5 Pernaute B, Spruce T, Rodriguez TA, Manzanares M. MiRNAmediated regulation of cell signaling and homeostasis in the early mouse embryo. Cell Cycle 2011; 10: 584-91.

6 Liang $\mathrm{LH}, \mathrm{He} \mathrm{XH}$. Macro-management of microRNAs in cell cycle progression of tumor cells and its implications in anti-cancer therapy. Acta Pharmacol Sin 2011; 32: 1311-20.

7 Lerner M, Lundgren J, Akhoondi S, Jahn A, Ng HF, Akbari Moqadam $\mathrm{F}$, et al. MiRNA-27a controls FBW7/hCDC4-dependent cyclin E degradation and cell cycle progression. Cell Cycle 2011; 10: 217283.

8 Du WW, Yang BB, Yang BL, Deng Z, Fang L, Shan SW, et al. Versican G3 domain modulates breast cancer cell apoptosis: a mechanism for breast cancer cell response to chemotherapy and EGFR therapy. PLoS One 2011; 6: e26396.

9 Fang L, Du WW, Yang W, Rutnam ZJ, Peng C, Li H, et al. MiR-93 enhances angiogenesis and metastasis by targeting LATS2. Cell Cycle 2012; 11: 4352-65.

10 Luo L, Ye G, Nadeem L, Fu G, Yang BB, Honarparvar E, et al. MicroRNA-378a-5p promotes trophoblast cell survival, migration and invasion by targeting Nodal. J Cell Sci 2012; 125: 3124-32.

11 Siragam V, Rutnam ZJ, Yang W, Fang L, Luo L, Yang X, et al. MicroRNA miR-98 inhibits tumor angiogenesis and invasion by targeting activin receptor-like kinase-4 and matrix metalloproteinase-11. Oncotarget 2012; 3:1370-85.

12 Du WW, Fang L, Li M, Yang X, Liang Y, Peng C, et al. MicroRNA
miR-24 enhances tumor invasion and metastasis by targeting PTPN9 and PTPRF to promote EGF signaling. J Cell Sci 2013; doi: 10.1242/ jcs.118299

13 Rutnam ZJ, Yang BB. The non-coding 3' UTR of CD44 induces metastasis by regulating extracellular matrix functions. J Cell Sci 2012; 125: 2075-85.

14 Kahai S, Lee SC, Lee DY, Yang J, Li M, Wang $\mathrm{CH}$, et al. MicroRNA miR-378 regulates nephronectin expression modulating osteoblast differentiation by targeting GaINT-7. PLoS One 2009; 4: e7535.

15 Wang CH, Lee DY, Deng Z, Jeyapalan Z, Lee SC, Kahai S, et al. MicroRNA miR-328 regulates zonation morphogenesis by targeting CD44 expression. PLoS One 2008; 3: e2420.

16 Lee DY, Shatseva T, Jeyapalan Z, Du WW, Deng Z, Yang BB. A 3'untranslated region ( $3^{\prime}$ UTR) induces organ adhesion by regulating miR-199a* functions. PLoS One 2009; 4: e4527.

17 Lee DY, Jeyapalan Z, Fang L, Yang J, Zhang Y, Yee AY, et al. Expression of versican 3 '-untranslated region modulates endogenous microRNA functions. PLoS One 2010; 5: e13599.

18 Jeyapalan Z, Deng Z, Shatseva T, Fang L, He C, Yang BB. Expression of CD44 3'-untranslated region regulates endogenous microRNA functions in tumorigenesis and angiogenesis. Nucleic Acids Res 2011; 39: 3026-41.

19 Lee SC, Fang L, Wang CH, Kahai S, Deng Z, Yang BB. A non-coding transcript of nephronectin promotes osteoblast differentiation by modulating microRNA functions. FEBS Lett 2011; 585: 2610-6.

20 Fang L, Du WW, Yang X, Chen K, Ghanekar A, Levy G, et al. Versican $3^{\prime}$-untranslated region ( $3^{\prime}$-UTR) functions as a ceRNA in inducing the development of hepatocellular carcinoma by regulating miRNA activity. FASEB J 2013; 27: 907-19.

21 Poliseno L, Salmena L, Zhang J, Carver B, Haveman WJ, Pandolfi PP. A coding-independent function of gene and pseudogene mRNAs regulates tumour biology. Nature 2010; 465: 1033-8.

22 Cesana M, Cacchiarelli D, Legnini I, Santini T, Sthandier O, Chinappi M, et al. A long noncoding RNA controls muscle differentiation by functioning as a competing endogenous RNA. Cell 2011; 147: 358-69. 
23 Rutnam ZJ, Wight TN, Yang BB. miRNAs regulate expression and function of extracellular matrix molecules. Matrix Biol 2012; 32:7485.

24 Shan SW, Lee DY, Deng Z, Shatseva T, Jeyapalan Z, Du WW, et al. MicroRNA MiR-17 retards tissue growth and represses fibronectin expression. Nat Cell Biol 2009; 11: 1031-8.

25 Vasudevan S, Tong Y, Steitz JA. Switching from repression to activation: microRNAs can up-regulate translation. Science 2007; 318: 1931-4.

26 Yang X, Rutnam ZJ, Jiao C, Wei D, Xie Y, Du J, et al. An anti-let-7 sponge decoys and decays endogenous let- 7 functions. Cell Cycle 2012; 11: 3097-108.

27 Li BA. A novel tumor suppressor miRNA miR-520e contributes to suppression of hepatoma. Acta Pharmacol Sin 2012; 33: 3-4.

28 Jiang Q, Wang Y, Hao Y, Juan L, Teng M, Zhang X, et al. miR2Disease: a manually curated database for microRNA deregulation in human disease. Nucleic Acids Res 2009; 37: D98-104.

29 Sun K, Wang W, Zeng JJ, Wu CT, Lei ST, Li GX. MicroRNA-221 inhibits CDKN1C/p57 expression in human colorectal carcinoma. Acta Pharmacol Sin 2011; 32: 375-84.

30 Yang S, Li Y. MicroRNAs: novel factors in clinical diagnosis and prognosis for nasopharyngeal carcinoma. Acta Pharmacol Sin 2012; 33: 981-2.

31 Ye G, Fu G, Cui S, Zhao S, Bernaudo S, Bai Y, et al. MicroRNA 376c enhances ovarian cancer cell survival by targeting activin receptorlike kinase 7: implications for chemoresistance. J Cell Sci 2011; 124: 359-68.

32 Rutnam ZJ, Yang BB. The involvement of microRNAs in malignant transformation. Histol Histopathol 2012; 27: 1263-70.

33 Fang L, Du WW, Yang W, Rutnam ZJ, Peng C, Li H, et al. MiR-93 enhances angiogenesis and metastasis by targeting LATS2. Cell Cycle 2012; 11: 4352-65.

34 Siragam V, Rutnam ZJ, Yang W, Fang L, Luo L, Yang X, et al. MicroRNA miR-98 inhibits tumor angiogenesis and invasion by targeting activin receptor-like kinase- 4 and matrix metalloproteinase- 11 . Oncotarget 2012; 3: 1370-85.

35 Wang D, Qiu C, Zhang H, Wang J, Cui Q, Yin Y. Human microRNA oncogenes and tumor suppressors show significantly different biological patterns: from functions to targets. PLoS One 2010; 5: e13067.

36 He L, Thomson JM, Hemann MT, Hernando-Monge E, Mu D, Goodson $\mathrm{S}$, et al. A microRNA polycistron as a potential human oncogene. Nature 2005; 435: 828-33.

37 Hossain A, Kuo MT, Saunders GF. Mir-17-5p regulates breast cancer cell proliferation by inhibiting translation of AIB1 mRNA. Mol Cell Biol 2006; 26: 8191-201.

38 Mateescu B, Batista L, Cardon M, Gruosso T, de Feraudy Y, Mariani 0 , et al. miR-141 and miR-200a act on ovarian tumorigenesis by controlling oxidative stress response. Nat Med 2011; 17: 1627-35.

39 Li H, Yang BB. Stress response of glioblastoma cells mediated by miR-17-5p targeting PTEN and the passenger strand miR-17-3p targeting MDM2. Oncotarget 2012; 3: 1653-68.

40 Shan SW, Fang L, Shatseva T, Rutnam ZJ, Yang X, Lu WY, et al. Mature MiR-17-5p and passenger miR-17-3p induce hepatocellular carcinoma by targeting PTEN, GaINT7, and vimentin in different signal pathways. J Cell Sci 2013; doi: 10.1242/jcs.122895

41 Baguley BC. Multiple drug resistance mechanisms in cancer. Mol Biotechnol 2010; 46: 308-16.

42 Liang Z, Li Y, Huang K, Wagar N, Shim H. Regulation of miR-19 to breast cancer chemoresistance through targeting PTEN. Pharm Res 2011; 28: 3091-100.
43 Kastl L, Brown I, Schofield AC. miRNA-34a is associated with docetaxel resistance in human breast cancer cells. Breast Cancer Res Treat 2012; 131: 445-54.

44 Shi GH, Ye DW, Yao XD, Zhang SL, Dai B, Zhang HL, et al. Involvement of microRNA-21 in mediating chemoresistance to docetaxel in androgen-independent prostate cancer PC3 cells. Acta Pharmacol Sin 2010; 31: 867-73.

45 Bao L, Hazari S, Mehra S, Kaushal D, Moroz K, Dash S. Increased expression of P-glycoprotein and doxorubicin chemoresistance of metastatic breast cancer is regulated by miR-298. Am J Pathol 2012; 180: 2490-503.

46 Zhu H, Wu H, Liu X, Evans BR, Medina DJ, Liu CG, et al. Role of microRNA miR-27a and miR-451 in the regulation of MDR1/ P-glycoprotein expression in human cancer cells. Biochem Pharmacol 2008; 76: 582-8.

47 Feng DD, Zhang $\mathrm{H}$, Zhang $\mathrm{P}$, Zheng YS, Zhang XJ, Han BW, et al. Down-regulated miR-331-5p and miR-27a are associated with chemotherapy resistance and relapse in leukaemia. J Cell Mol Med 2011; 15: 2164-75.

48 Bourguignon LY, Spevak CC, Wong G, Xia W, Gilad E. HyaluronanCD44 interaction with protein kinase $\mathrm{C}$ (epsilon) promotes oncogenic signaling by the stem cell marker Nanog and the production of microRNA-21, leading to down-regulation of the tumor suppressor protein PDCD4, anti-apoptosis, and chemotherapy resistance in breast tumor cells. J Biol Chem 2009; 284: 26533-46.

49 Zhu X, Li Y, Shen H, Li H, Long L, Hui L, et al. miR-137 restoration sensitizes multidrug-resistant MCF-7/ADM cells to anticancer agents by targeting YB-1. Acta Biochim Biophys Sin (Shanghai) 2013; 45: 80-6.

50 Chen J, Tian W, Cai H, He H, Deng Y. Down-regulation of microRNA$200 c$ is associated with drug resistance in human breast cancer. Med Oncol 2012; 29: 2527-34.

51 Kovalchuk O, Filkowski J, Meservy J, IInytskyy Y, Tryndyak VP, Chekhun VF, et al. Involvement of microRNA-451 in resistance of the MCF-7 breast cancer cells to chemotherapeutic drug doxorubicin. Mol Cancer Ther 2008; 7: 2152-9.

52 Asuthkar S, Velpula KK, Chetty C, Gorantla B, Rao JS. Epigenetic regulation of miRNA-211 by MMP-9 governs glioma cell apoptosis, chemosensitivity and radiosensitivity. Oncotarget 2012; 3: 143954.

53 Ikemura K, Yamamoto M, Miyazaki S, Mizutani H, Iwamoto T, Okuda M. Microrna-145 post-transcriptionally regulates the expression and function of P-glycoprotein in intestinal epithelial cells. Mol Pharmacol 2013; 83: 399-405.

54 Boyerinas B, Park SM, Murmann AE, Gwin K, Montag AG, Zillhardt $\mathrm{M}$, et al. Let-7 modulates acquired resistance of ovarian cancer to Taxanes via IMP-1-mediated stabilization of multidrug resistance 1. Int J Cancer 2012; 130: 1787-97.

55 Li Z, Hu S, Wang J, Cai J, Xiao L, Yu L, et al. MiR-27a modulates MDR1/P-glycoprotein expression by targeting HIPK2 in human ovarian cancer cells. Gynecol Oncol 2010; 119: 125-30.

56 Yang L, Li N, Wang H, Jia X, Wang X, Luo J. Altered microRNA expression in cisplatin-resistant ovarian cancer cells and upregulation of miR-130a associated with MDR1/P-glycoprotein-mediated drug resistance. Oncol Rep 2012; 28: 592-600.

57 Xu Y, Xia F, Ma L, Shan J, Shen J, Yang Z, et al. MicroRNA-122 sensitizes HCC cancer cells to adriamycin and vincristine through modulating expression of MDR and inducing cell cycle arrest. Cancer Lett 2011; 310: 160-9.

58 Zhao X, Yang L, Hu J, Ruan J. miR-138 might reverse multidrug resistance of leukemia cells. Leuk Res 2010; 34: 1078-82. 
59 Fujita Y, Kojima K, Ohhashi R, Hamada N, Nozawa Y, Kitamoto A, et al. MiR-148a attenuates paclitaxel resistance of hormone-refractory, drug-resistant prostate cancer PC3 cells by regulating MSK1 expression. J Biol Chem 2010; 285: 19076-84.

60 Liang Z, Wu H, Xia J, Li Y, Zhang Y, Huang K, et al. Involvement of miR-326 in chemotherapy resistance of breast cancer through modulating expression of multidrug resistance-associated protein 1. Biochem Pharmacol 2010; 79: 817-24.

61 Pan YZ, Morris ME, Yu AM. MicroRNA-328 negatively regulates the expression of breast cancer resistance protein (BCRP/ABCG2) in human cancer cells. Mol Pharmacol 2009; 75: 1374-9.

62 Nakatani F, Ferracin M, Manara MC, Ventura S, Del Monaco V, Ferrari $\mathrm{S}$, et al. miR-34a predicts survival of Ewing's sarcoma patients and directly influences cell chemosensitivity and malignancy. J Pathol 2012; 226: 796-805.

63 Zhu X, Li H, Long L, Hui L, Chen H, Wang X, et al. miR-126 enhances the sensitivity of non-small cell lung cancer cells to anticancer agents by targeting vascular endothelial growth factor A. Acta Biochim Biophys Sin (Shanghai) 2012; 44: 519-26.

64 Seike M, Goto A, Okano T, Bowman ED, Schetter AJ, Horikawa I, et al. MiR-21 is an EGFR-regulated anti-apoptotic factor in lung cancer in never-smokers. Proc Natl Acad Sci U S A 2009; 106: 12085-90.

65 Zhou X, Ren Y, Moore L, Mei M, You Y, Xu P, et al. Downregulation of miR-21 inhibits EGFR pathway and suppresses the growth of human glioblastoma cells independent of PTEN status. Lab Invest 2010; 90 : 144-55.

66 Cho WC, Chow AS, Au JS. MiR-145 inhibits cell proliferation of human lung adenocarcinoma by targeting EGFR and NUDT1. RNA Biol 2011; 8: 125-31.

67 Zhu H, Dougherty U, Robinson V, Mustafi R, Pekow J, Kupfer S, et al. EGFR signals downregulate tumor suppressors miR-143 and miR-145 in Western diet-promoted murine colon cancer: role of G1 regulators. Mol Cancer Res 2011; 9: 960-75.

68 Darido C, Georgy SR, Wilanowski T, Dworkin S, Auden A, Zhao Q, et al. Targeting of the tumor suppressor GRHL3 by a miR-21-dependent proto-oncogenic network results in PTEN loss and tumorigenesis. Cancer Cell 2011; 20: 635-48.

69 Zhang LY, Ho-Fun Lee V, Wong AM, Kwong DL, Zhu YH, Dong SS, et al. MicroRNA-144 promotes cell proliferation, migration and invasion in nasopharyngeal carcinoma through repression of PTEN. Carcinogenesis 2013; 34: 454-63.

70 Wang YS, Wang YH, Xia HP, Zhou SW, Schmid-Bindert G, Zhou CC. MicroRNA-214 regulates the acquired resistance to gefitinib via the PTEN/AKT pathway in EGFR-mutant cell lines. Asian Pac J Cancer Prev 2012; 13: 255-60.

71 Ernst A, Campos B, Meier J, Devens F, Liesenberg F, Wolter M, et al. De-repression of CTGF via the miR-17-92 cluster upon differentiation of human glioblastoma spheroid cultures. Oncogene 2010; 29: 3411-22.

72 McKinsey EL, Parrish JK, Irwin AE, Niemeyer BF, Kern HB, Birks DK, et al. A novel oncogenic mechanism in Ewing sarcoma involving IGF pathway targeting by EWS/Fli1-regulated microRNAs. Oncogene 2011; 30: 4910-20.

73 Rai K, Takigawa N, Ito S, Kashihara H, Ichihara E, Yasuda T, et al. Liposomal delivery of microRNA-7-expressing plasmid overcomes epidermal growth factor receptor tyrosine kinase inhibitor-resistance in lung cancer cells. Mol Cancer Ther 2011; 10: 1720-7.

74 Kandouz M, Batist G. Gap junctions and connexins as therapeutic targets in cancer. Expert Opin Ther Targets 2010; 14: 681-92.

75 Yang B, Lin H, Xiao J, Lu Y, Luo X, Li B, et al. The muscle-specific microRNA miR-1 regulates cardiac arrhythmogenic potential by targeting GJA1 and KCNJ2. Nat Med 2007; 13: 486-91.

76 Anderson C, Catoe H, Werner R. MIR-206 regulates connexin43 expression during skeletal muscle development. Nucleic Acids Res 2006; 34: 5863-71.

77 Kedde M, Strasser MJ, Boldajipour B, Oude Vrielink JA, Slanchev K, le Sage $C$, et al. RNA-binding protein Dnd1 inhibits microRNA access to target mRNA. Cell 2007; 131: 1273-86.

78 Elhassan MO, Christie J, Duxbury MS. Homo sapiens systemic RNA interference-defective-1 transmembrane family member 1 (SIDT1) protein mediates contact-dependent small RNA transfer and microRNA-21-driven chemoresistance. J Biol Chem 2012; 287: $5267-77$.

79 Zhao Y, Deng C, Lu W, Xiao J, Ma D, Guo M, et al. let-7 microRNAs induce tamoxifen sensitivity by downregulation of estrogen receptor alpha signaling in breast cancer. Mol Med 2011; 17: 1233-41.

80 Adams BD, Furneaux H, White BA. The micro-ribonucleic acid (miRNA) miR-206 targets the human estrogen receptor-alpha (ERalpha) and represses ERalpha messenger RNA and protein expression in breast cancer cell lines. Mol Endocrinol 2007; 21: 1132-47.

81 Zhao JJ, Lin J, Yang H, Kong W, He L, Ma X, et al. MicroRNA-221/222 negatively regulates estrogen receptor alpha and is associated with tamoxifen resistance in breast cancer. J Biol Chem 2008; 283: 31079-86.

82 Mohri T, Nakajima M, Takagi S, Komagata S, Yokoi T. MicroRNA regulates human vitamin D receptor. Int J Cancer 2009; 125: 132833.

83 Tsuchiya Y, Nakajima M, Takagi S, Taniya T, Yokoi T. MicroRNA regulates the expression of human cytochrome P450 1B1. Cancer Res 2006; 66: 9090-8.

84 Martinez VG, O'Connor R, Liang Y, Clynes M. CYP1B1 expression is induced by docetaxel: effect on cell viability and drug resistance. $\mathrm{Br}$ J Cancer 2008; 98: 564-70.

85 Choi YM, An S, Lee EM, Kim K, Choi SJ, Kim JS, et al. CYP1A1 is a target of miR-892a-mediated post-transcriptional repression. Int J Oncol 2012; 41: 331-6.

86 Chen F, Chen C, Yang S, Gong W, Wang Y, Cianflone K, et al. Let$7 \mathrm{~b}$ inhibits human cancer phenotype by targeting cytochrome P450 epoxygenase 2J2. PLoS One 2012; 7: e39197.

87 Wang $\mathrm{Y}$, Hu HH, Pang H, Zhou XY, Yu LS, Wang LL, et al. Lentiviral transgenic microRNA-based shRNA suppressed mouse cytochromosome P450 3A (CYP3A) expression in a dose-dependent and inheritable manner. PLoS One 2012; 7: e30560.

88 Zhang Y, Yang JM. The impact of cellular senescence in cancer therapy: is it true or not? Acta Pharmacol Sin 2011; 32: 1199-207.

89 Pommier Y, Sordet O, Antony S, Hayward RL, Kohn KW. Apoptosis defects and chemotherapy resistance: molecular interaction maps and networks. Oncogene 2004; 23: 2934-49.

90 Cittelly DM, Das PM, Salvo VA, Fonseca JP, Burow ME, Jones FE. Oncogenic HER2\{Delta\}16 suppresses miR-15a/16 and deregulates BCL-2 to promote endocrine resistance of breast tumors. Carcinogenesis 2010; 31: 2049-57.

91 Dong J, Zhao YP, Zhou L, Zhang TP, Chen G. Bcl-2 upregulation induced by miR-21 via a direct interaction is associated with apoptosis and chemoresistance in MIA PaCa-2 pancreatic cancer cells. Arch Med Res 2011; 42: 8-14.

92 Shi L, Chen J, Yang J, Pan T, Zhang S, Wang Z. MiR-21 protected human glioblastoma U87MG cells from chemotherapeutic drug temozolomide induced apoptosis by decreasing Bax/Bcl-2 ratio and caspase-3 activity. Brain Res 2010; 1352: 255-64.

93 Zhou M, Liu Z, Zhao Y, Ding Y, Liu H, Xi Y, et al. MicroRNA-125b confers the resistance of breast cancer cells to paclitaxel through 
suppression of pro-apoptotic Bcl-2 antagonist killer 1 (Bak1) expression. J Biol Chem 2010; 285: 21496-507.

94 Zhao A, Zeng Q, Xie X, Zhou J, Yue W, Li Y, et al. MicroRNA-125b induces cancer cell apoptosis through suppression of $\mathrm{Bcl}-2$ expression. J Genet Genomics 2012; 39: 29-35.

95 Zang YS, Zhong YF, Fang Z, Li B, An J. MiR-155 inhibits the sensitivity of lung cancer cells to cisplatin via negative regulation of Apaf-1 expression. Cancer Gene Ther 2012; 19: 773-8.

96 Lee DY, Deng Z, Wang CH, Yang BB. MicroRNA-378 promotes cell survival, tumor growth, and angiogenesis by targeting SuFu and Fus-1 expression. Proc Natl Acad Sci U S A 2007; 104: 20350-5.

97 Weis SM, Cheresh DA. Tumor angiogenesis: molecular pathways and therapeutic targets. Nat Med 2011; 17: 1359-70.

98 Fang L, Deng Z, Shatseva T, Yang J, Peng C, Du WW, et al. MicroRNA miR-93 promotes tumor growth and angiogenesis by targeting integrin-beta8. Oncogene 2011; 30: 806-21.

99 Png KJ, Halberg N, Yoshida M, Tavazoie SF. A microRNA regulon that mediates endothelial recruitment and metastasis by cancer cells. Nature 2012; 481: 190-4.

100 Bonauer A, Carmona G, Iwasaki M, Mione M, Koyanagi M, Fischer A, et al. MicroRNA-92a controls angiogenesis and functional recovery of ischemic tissues in mice. Science 2009; 324: 1710-3.

101 Potente M, Gerhardt H, Carmeliet P. Basic and therapeutic aspects of angiogenesis. Cell 2011; 146: 873-87.

102 Hua Z, Lv Q, Ye W, Wong CK, Cai G, Gu D, et al. MiRNA-directed regulation of VEGF and other angiogenic factors under hypoxia. PLoS One 2006; 1: e116.

103 Mekenkamp $\sqcup$, Tol J, Dijkstra JR, de Krijger I, Vink-Borger ME, van Vliet S, et al. Beyond KRAS mutation status: influence of KRAS copy number status and microRNAs on clinical outcome to cetuximab in metastatic colorectal cancer patients. BMC Cancer 2012; 12: 292.

104 Ghosh AK, Shanafelt TD, Cimmino A, Taccioli C, Volinia S, Liu CG, et al. Aberrant regulation of $\mathrm{PVHL}$ levels by microRNA promotes the
HIF/VEGF axis in CLL B cells. Blood 2009; 113: 5568-74.

105 Visvader JE, Lindeman GJ. Cancer stem cells in solid tumours: accumulating evidence and unresolved questions. Nat Rev Cancer 2008; 8: 755-68.

106 Liu C, Tang DG. MicroRNA regulation of cancer stem cells. Cancer Res 2011; 71: 5950-4.

107 Yu F, Yao H, Zhu P, Zhang X, Pan Q, Gong C, et al. let-7 regulates self renewal and tumorigenicity of breast cancer cells. Cell 2007; 131: 1109-23.

108 Liu C, Kelnar K, Liu B, Chen X, Calhoun-Davis T, Li H, et al. The microRNA miR-34a inhibits prostate cancer stem cells and metastasis by directly repressing CD44. Nat Med 2011; 17: 211-5.

109 Ma S, Tang KH, Chan YP, Lee TK, Kwan PS, Castilho A, et al. miR$130 \mathrm{~b}$ promotes $\mathrm{CD} 133^{+}$liver tumor-initiating cell growth and selfrenewal via tumor protein 53-induced nuclear protein 1. Cell Stem Cell 2010; 7: 694-707.

110 Deng Z, Yang X, Fang L, Rutnam ZJ, Yang BB. Misprocessing and functional arrest of microRNAs by miR-Pirate: roles of miR-378 and miR-17. Biochem J 2013; 450: 375-86.

111 Wu QP, Xie YZ, Deng Z, Li XM, Yang W, Jiao CW, et al. Ergosterol peroxide isolated from Ganoderma lucidum abolishes microRNA miR378-mediated tumor cells on chemoresistance. PLoS One 2012; 7: e44579.

112 Mendell JT, Olson EN. MicroRNAs in stress signaling and human disease. Cell 2012; 148: 1172-87.

This work is licensed under the Creative Commons Attribution-NonCommercial-No Derivative Works 3.0 Unported License. To view a copy of this license, visit http://creativecommons.org/licenses/ by-nc-nd/3.0/ 